\title{
A Review on the Methods of Evaluating the New Approaches Proposed in the Agile Context
}

\author{
Hamzah Alaidaros \\ Faculty of Computer Science and \\ Engineering \\ Al-Ahgaff University \\ Mukalla, Hadramaout, Yemen \\ Email:m7amza7 [AT] yahoo.com
}

\author{
Mazni Omar \\ Institute for Advanced and Smart \\ Digital Opportunities (IASDO), \\ School of Computing \\ UUM College of Arts and Sciences \\ UniversitiUtara Malaysia, 06010 \\ UUM Sintok, Kedah, Malaysia \\ Email:mazni [AT] uum.edu.my
}

\author{
Rohaida Romli \\ Human-Centred Computing \\ Res earch Lab, Schoolof Computing \\ UUM College of Arts and Sciences \\ Universiti Utara Malaysia, 06010 \\ UUM Sintok, Kedah, Malaysia \\ Email:aida [AT] uum.edu.my
}

\begin{abstract}
In the recent years, Agile is being one of the emerging technologies adopted by numerous organizations. The Agile technology has not obtained an extensive acceptance in the software de velopment organizations (SDOs), but it is also being broadly employed in different fields and environments. Accordingly, new approaches have been proposed by researchers and practitioners based on the Agile context, however, the re is scarce and - sometimes - absence of describing the evaluation process of these approaches. Therefore, this paper reports the findings of an extensive literature search on how the new proposed approaches are being evaluated. The narrative review me thodology was employed to criticize and summarize a body of literature retrieved from various scientific sources. The results reveal that there are various methods used for evaluating the proposed Agile approaches. Nevertheless, this re view focuses on explaining the five common methods, which are: (1) case study, (2) survey, (3) interview, (3) focus group, and (5) expert review. Thereafter, the authors discuss the key findings and highlight directions for future researches. This study tends to help researchers and practitioners to select the suitable evaluation methods when constructing new Agile approaches.
\end{abstract}

Keywords-Agile methods; evaluation, new approach; review; software engineering

\section{INTRODUCTION}

In software engineering (SE), a software development method is defined as "a splitting of software development work into distinct phases containing activities with the intent of better planning and management" [1]. However, even by applying the existing project management methods, such projects often failed to be delivered on time and within budget. Therefore, several methods have been established for developing software projects since the inception of information technology (IT). These include traditional methods, such as waterfall, which have distinct phases, and Agile methods, which define an iteration process that allows designing, constructing, and deploying different parts of software simultaneously [2].

Recently, Agile is being one of the emerging technologies adopted by numerous companies particularly in the software development organizations (SDOs). This is because Agile has several characteristics and distinguished features compared to the traditional approaches [3]. According to the Global Project Management [4] survey, $71 \%$ of the participating organizations report greater agility over the last five years signifying that agility is recognized in helping them to remain competitive. Moreover, according to the survey [5], the most organizations (97\%) practice Agile methods. In another survey, $60 \%$ of the IT professionals use Agile methods, whilst 38\% use the combination of Agile and other methods as stated in Interop ITX Res earch Report [6]

Bhatt, et al. [7] claimed that healthcare organization should be Agile in order to provide the best healthcare services to the patient with cost optimization. Mainly, Agile methods have been implemented in different fields, such as engineering, medicine, banking, and manufacturing [8]. Nawaz and Gomes [9] stated that organizations adopt the Agile methods to move quickly and respond to market needs and services. Hence, Agile methods are being used extensively in different project sizes and environments, rather than focusing only on the primary intended scope [10]. Accordingly, altemative approaches of Agile methods have been developed, enhanced, and integrated with other methods in order to support the increased demand of various project environments [11][12]. In this study, the term "approach" refers to any proposed model, method, methodology, framework, or technique in the Agile context.

The existing studies proposed new Agile approaches only focus on their development stages. However, these studies did not describe how proposed approaches are being evaluated [10] although the evaluation process is an essential stage in establishing a new approach as claimed by Silva, et al. [13]. For example, a theoretical framework has been established by Alaidaros, et al. [14] to improve the progress monitoring task of the Agile Kanban method. Nonetheless, authors acknowledged that this framework still needs an extended study for further enhancement, in which its potential evaluation dimensions should be examined and appended to the proposed framework. Hence, the current study aims at reviewing the methods used to evaluate the new proposed A gile approaches. 
The reminder of this paper is structured so the following section (section II) explains the research methodology followed to accomplish the study aim. After that, section III presents explanation about the literature of the most methods used for evaluating the new approaches proposed in the Agile context. Then, the study findings are discussed and analysed in section IV. Finally, conclusion, limitations, and insights for future researches are given in the final section.

\section{MethodOLOGY}

In doing a research, methodology is the most important stage to come out with a good and useful study. A methodology is defined as a set of principles, activities, and procedures, which guide the researcher, manager, and practitioner to select a suitable method to a particular study [15]. The methodology addresses all required procedures that are taken to answer the research questions and accomplish the researchobjectives.

The main aim of this study is to explore how well proposed Agile approaches by SE researches and practitioners are evaluated. As part of this work, we aimed to answer the following research question: What are the methods used to evaluate the new approaches proposed in the Agile context? Therefore, the relevant literature has been reviewed in order to gain insights and ideas about the current problem [16], as the literature is rife with gaps which require more in-depth investigation [17].

This study adapted the narrative review methodology, which is employed to criticize and summarize a body of literature, and then draws a conclusion of research topics. In addition, the narrative review synthesizes the current literature to focus on a subset of information, in which different sources are used and thus this review goes beyond the more rigid systematic review [18]. Fig.1 shows the three procedures followed to achieve this study objective. The procedures are: (1) Review the literature, (2) Identify the related literature, and (3) Analyse and discuss the findings.

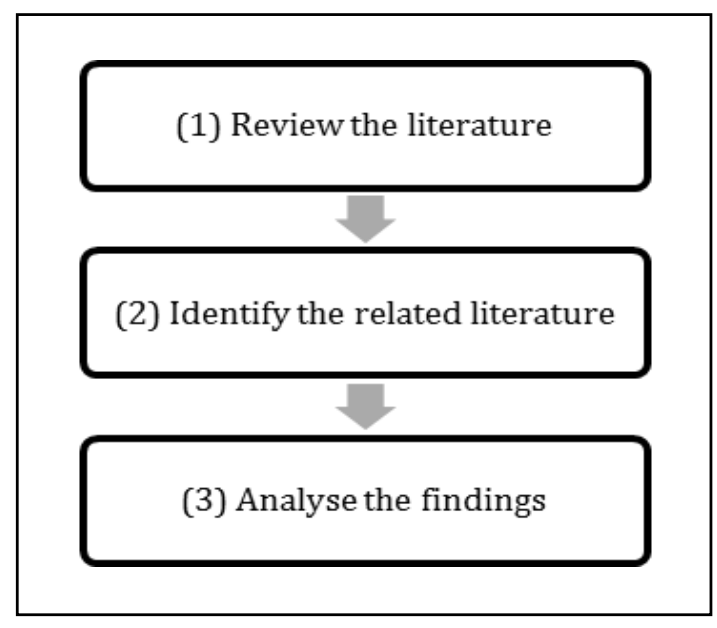

Figure 1. Study procedures
In the first procedure, the literature survey method was used to extensively explore the related works and relevant studies. Machi and McEvoy [19] confirm that this method is used to collect main ideas and information through revision of the related joumals, proceeding papers, books, thes is, blogs, and reports. Secondly, the retrieved literatures were skimmed through to understand and identify if the literature is related to the field of research. In this procedure, a qualitative analys is for the retrieved literatures was conducted in order to answer the above research question. The qualitative analys is is an appropriate approach used to enable researchers understanding and investigating the topic in depth and in greater details. It involves analysing and interpreting texts and interviews to discover pattems seeking to describe a specific issue [20]. The content analys is technique was used to explain the research findings, whereby the results of literature review were identified, coded, and categorized into primary pattems [21]. The final procedure was carried out to discuss the findings and highlight its major implication to the body of knowledge. Subsequently, future directions were also identified based on the knowledge gained from this study.

\section{RESUlts}

There are various methods used for evaluating the proposed Agile approaches. This review is limited to explain the five common methods, which are: (1) case study, (2) survey, (3) interview, (3) focus group, and (5) expert review. The popularity of these methods is evidenced from a recent systematic literature review conducted by Alaidaros, et al. [10]. These five methods are subsequently described by providing their objectives and illustrating the appropriate types of ques tions to be best addressed.

\section{A. Case Study}

The case study method is an empirical inquiry involving a study of a case within a real-life, contemporary context or setting [22]. Case study offers deep understanding of the existence of certain phenomena and reveals the mechanisms of the cause-effect relationships occurrence [23]. In this vein, Yin [24] stated that a case study research is used when a researcher wants to understand a real-world case and when such understanding is likely to involve important contextual conditions pertinent to the case. In this method, qualitative data are usually collected using interview, observations, or group discussions. It plays a central role, and offers rich insights into the case. Data collection is always performed with respect to a well-defined unit of analysis. In the SE research, the unit of analysis might be a company, a project, a team, an individual developer, a particular episode or event, a specific work product, and others. A case study can be used to practically validate a tool, method, or model in SDOs [23, 25].

Altarawneh [26] indicated that the case study method is often used as a plain working example of a newly proposed approach that is applied to a limited number of respondents. The participants in a case study can be a small team cons is ts of at least two members. The team with a small number of members helps in enhancing interpersonal communication 
skills [27] as well as being highly efficient [28]. Therefore, the two members of a team participated in a case study would be an adequate number for achieving valid and reliable results of the evaluation.

\section{B. Survey}

Survey is a retrospective study of a situation that investigates relationships and outcomes from a large scale of population or individuals. According to Sekaran and Bougie [29], survey is a useful and powerful method that is commonly used to measure opinions and awareness. Although most closely associated with the use of questionnaires for data collection, survey can also be conducted by using structured interviews or data logging techniques. Survey is particularly well-suited to studies that are conducted to answer what, how much, and how many questions [23, 25]. Currently, an online survey is being widely adopted as it is an optimal approach used for collecting data from a large intemational despondences [30]. Pahurkar, et al. [31] indicated that data that is collected through the online survey study can increase its sample size.

\section{Interview}

The interview method is used to collect primary data by interviewing a number of respondents about existing facts and their opinions. It provides a thorough information on a certain situation. The interview is time saving method in which the interviewees provide their answers based on the questions asked [22, 32]. A semi-structured interview is a technique commonly used in conducting an interview method because it allows the interviewer to be prepared and appeared competent during the interview session. It also offers interviewees the freedom to express their insights without primness [33]. The semi-structured interview provides comparable and reliable qualitative data [34]. Furthermore, the interview method is used for the data collection purpose when us ing case studies or surveys [35].

\section{Focus Group}

Focus group is an empirical method used to obtain feedback from software practitioners on designed models or prototypes. It is a suitable method used to obtain qualitative insights on how approaches or concepts are presented [36]. Focus group method is usually conducted in a semi-structured group session, moderated by a group leader or researcher, held in an informal setting with the purpose of collecting information on a designated topic. This method, which can be conducted easily, provides rich source of information and quick valuable feedbacks at low cost [37].

According to Bhat [38], the focus group method is very useful especially to a research related to new products and test new concepts. One of its strengths is the discovery of new insights due to the interactive nature of the setting and different backgrounds of the participants [39]. Moreover, Singer, et al. [40] affirmed that there are two important side benefits of the focus group; (1) introducing the participants to each other and (2) offering the sense of involvement in the research process to all participants. This method is often adopted and applied by the SE researchers in different evaluation studies to obtain experts' opinions. For instance, Mohamed [41] adopted this approach to evaluate the practicability of her proposed model in the real life environment. However, she stated that it is often difficult to schedule a focus group session with the busy schedules of the software practitioners.

Since the purpose of conducting the focus group session is to evaluate the proposed approaches and explore participants' experiences on its effectiveness and applicability, Krueger and Casey [42] point out that small group is preferable in the evaluation purpose because it is more comfortable for the participants to share their extensive experiences. Nevertheless, there are different opinions pertaining to the suitable number of participants for a focus group. For example, Wibeck [43] believes that four to six participants are sufficient, while Hummelvoll [44] suggests the ideal number of five to eight. For the others, six to ten should be the optimal number of participants in a focus group $[41,45]$.

\section{E. Expert Review}

The expent review is a simple method used to detect and remove defects [24]. According to Morgan [46], the expert review is employed by researchers to gather valid and reliable data -from experts - that concems with an identified problem. In the SE field, this method is commonly focused on yielding the academic and practitioners opinions in order to verify the proposed approaches design prior to the final evaluation [47, 48]. The knowledge experts can provide unique perspectives on the proposed approaches that allow researchers to obtain high reliability data. They can clarify the significance of those approaches as well as highlighting their strengths and weaknesses based on their thorough researches and academician experiences. Besides that, the domain experts may offer valued perceptions gained through their real setting, in which the proposed model designed with the intension that it would be practiced by team members in the software organizations $[41,49,50]$. The recommendations and suggestions provided by experts are utilized in the improvement of the final model $[49,50]$.

In the expert review method, there are different opinions related to the suitable number of participants. In a recent study conducted by Omar, et al. [51], six experts had participated in the initial evaluation of their proposed model. Authors confirm that this number of experts is suffice, in which five experts from a pertinent domain would be adequate. In fact, Shneiderman, et al. [52] mentioned that the sufficient number of experts involved in the expert review should be between three to five. As for Molich [53], one domain expert should be enough for such review. However, involving additional experts are recommendable if the expenses are affordable.

\section{DISCUSSION}

This section discusses the study results and highlights its key findings. Initially, in order to guide and assist the researchers to choose the potential evaluation methods, a comparis on between the five methods, which have been 
previously described, is summarized in Table 1 . The comparis on was conducted according to five criteria, which are researcher control, focus, cost, time, and sample size. These five criteria were extracted from different studies such as Easterbrook, et al. [23], Yin [24], and Malhotra [25]. Researcher control refers to what extent researcher controls the situation, with direct, precise, and systematic manipulation of the behaviour of the phenomenon to be studied. Focus refers to the effort of the investigation in terms of how the researcher will investigate the phenomenon. Cost refers to the amount of money incurred while performing the method and time criterion refers to the period required. The sample size denotes the number of targeted respondents that are identified to perform the method.

TABLE I. A COMPARISON BETWEEN EVALUATION METHODS

\begin{tabular}{|c|c|c|c|c|c|c|}
\hline NO & Method & $\begin{array}{c}\text { Researcher } \\
\text { Control }\end{array}$ & Focus & Cost & Time & $\begin{array}{c}\text { Sample } \\
\text { Size }\end{array}$ \\
\hline 1 & $\begin{array}{c}\text { Case } \\
\text { study }\end{array}$ & Low & $\begin{array}{c}\text { How \& } \\
\text { Why }\end{array}$ & Medium & High & $\begin{array}{c}\text { Large } \\
\& \\
\text { Small }\end{array}$ \\
\hline 2 & Survey & Low & $\begin{array}{c}\text { How } \\
\text { many } \\
\& \text { How } \\
\text { much }\end{array}$ & Low & Low & Large \\
\hline 3 & Interview & High & $\begin{array}{c}\text { How \& } \\
\text { Why }\end{array}$ & Low & High & Small \\
\hline 4 & $\begin{array}{c}\text { Focus } \\
\text { Group }\end{array}$ & High & $\begin{array}{c}\text { How \& } \\
\text { Why }\end{array}$ & Low & $\begin{array}{c}\text { Very } \\
\text { Low }\end{array}$ & Small \\
\hline 5 & $\begin{array}{c}\text { Expert } \\
\text { Review }\end{array}$ & High & $\begin{array}{c}\text { How \& } \\
\text { Why }\end{array}$ & Low & Low & Small \\
\hline
\end{tabular}

As shown in Table 1, it is obvious that the case study method focuses on how and why questions, and is suitable for large and s mall sized samples. However, the method gives less control to researcher and consumes considerable cost and time. The survey method does not support researcher control and concentrates on how many and how much questions. Although utilizes lower cost and time, this method is only suitable for a large sample size. On the other hand, the interview method has a high support for researcher control and concentrates on the how and why questions. This method is only suitable forsmall sized sample and consumes much time but with low cost.

The focus group and expert review methods provide high control of the researcher, focus on the how and why questions. Both methods are suitable for small sized sample and consume a limited cost when conducted. Nevertheless, focus group requires lower time (maximum three hours) when compared to the expert review.

Based on the above comparisons, the key findings of this study are presented in the following points:

- The expert review is a popular method used to yield the experts opinions on proposed approaches design to detect and remove defects. This method is usually adopted to initially verify the elements included in the proposed approaches by the knowledge and domain experts. The knowledge experts can give useful opinions on the proposed approaches based on their divers' years of experiences in the academician setting. Nonetheless, the domain experts can provide feedback from the industrial perspective as the proposed Agile approaches are directed to meet their needs.

- The focus group method is an empirical approach used to obtain qualitative insights on how the proposed approach is presented. This method is employed to evaluate the final approach design by verifying its effectiveness and validating its applicability in the real environment.

- Bräuer, et al. [36] affirmed that the focus group tumed out to be the most extremely adopted in the evaluation process of the approaches proposed in the Agile context and within the SEres earch community.

- The case studies and surveys are the most methods used for the evaluation purposes as revealed by Alaidaros, et al. [10]. Besides that, the case studies are conducted to validate the applicability of the proposed Agile approaches and increase their generalizability.

\section{CONCLUSION, LIMIT ATIONS, AND FUTURE DiRECTIONS}

This study confirms that the adoption of Agile methods is being increased by various organizations and environments. As it is an emerging technology received a wide acceptance, organizations have employed the Agile methods to move quickly and respond to market needs and services. As a result, different approaches have been proposed by organizations based on the Agile context, but from different perspectives and fields. However, these approaches are lacking of how its effectivenessand applicability are being evaluated.

Thus, this paper has explored the methods used for evaluating the proposed Agile approaches using the narrative review methodology. Although the results revealed that there are many evaluation methods, this review was limited to explain the five common methods, which are: case study, survey, interview, focus group, and expert review. In addition, this paper presented a comparison between these methods and highlighted their strengths and weaknesses.

Future work will focus to explore the remaining evaluation methods as the current review was limited to five methods. Moreover, it is hoped to extend this study by illustrating the detailed activities and steps of conducting each method. Overall, the present study contributes to the existing studies and researches pertaining the methods used for evaluating the new approaches proposed in the Agile context. Furthermore, this study would benefit researchers and practitioners from the SE field - or other fields - to choose the appropriate evaluation methods when they tend to construct new Agile approaches.

\section{ACKNOWLEDGMENT}

The authors would like to express their sincere gratitude to the Universiti Utara Malaysia, Malaysia and Al-Ahgaff University, Yemen for the financial ass istance that made this work possible. 


\section{REFERENCES}

[1] A. T. Al Ajeeli, "A framework for software development product methodology management," International Journal of Emerging Trends \& Technology in Computer Science (IJETTCS), vol. 5, pp. 43-57, July August 2016.

[2] I. Sommerville, Software Engineering, 10th ed. Harlow, United Kingdom: Pearson Education, 2016.

[3] H. Alaidaros, M. Omar, and R. Romli, "Towards an improved soffware project monitoring task model of Agile Kanban method," International Journal of Supply Chain Management (IJSCM), vol. 7, pp. 118-125, 2018.

[4] Global Project Management, "Success in Disruptive Times, 10th Global Project Managem ent Survey "Newtown Square: Project Management Institute, Inc2018

[5] Version One. (2018, 10 Feb 2019). 12th Annual State of Agile Development Survey.

[6] Interop ITX Research Report. (2017, 22 Oct 2017). State of DevOps. Available: http://www.interop.com/

[7] V. Bhatt, S. Chakraborty, and T. Chakravorty, "Importance of Digitech Adoption for Providing Efficient Healthcare Services during COVID19," International Journal on Emerging Technologies, vol. 11, pp. 01-13, 2020.

[8] H. Alaidaros and M. Omar, "Soffware Project Manag ement Approach es for Monitoring Work-In-Progress: A Review," Journal of Engineering and Applied Sciences, vol. 12, pp. 3851-3857, 2017.

[9] N. Nawaz and A. M. Gomes, "EDITTDA Approach for Agile Human Resource Perform ance in Bangalore Software Industry.," International Journal on Emerging Technologies, vol. 10, pp. 413-417, 2019.

[10] H. Alaidaros, M. Omar, and R. Romli, "The Key Factors of Evaluating Agile Approaches: A Systematic Literature Review," International Journal of Supply Chain Management (IJSCM), vol. 8, pp. 954-964, 2019.

[11] E. Papadakis and L Tsironis, "Hybrid methods and practices associated with Agile methods, method tailoring and delivery of projects in a nonsoftware context," Procedia computer science, vol. 138, pp. 739-746, 2018.

[12] V. Dattatreya, K. C. Rao, and V. Rayudu, "Applying Agile programming and design patterns in IT domain," in Emerging Trends in Electrical, Communications and Information Technologies, Singapore, 2017, pp. 71-78

[13] V. B. Silva, F. Schramm, and A. C. Damasceno, "A multicriteria approach for selection of agile methodologies in software development projects," in 2016 IEEE International Con ference on Systems, Man, and Cybernetics (SMC), Budapest, Hungary, 2016, pp. 002056-002060.

[14] H. Alaidaros, M. Omar, and R. Romli, "A Theoretical Framework for Improving Software Project Monitoring Task of Agile Kanban Method," in Recent Trends in Data Science and Soft Computing. IRICT 2018. Advances in Intelligent Systems and Computing. vol. 843, F. Saeed, N. Gazem, F. Mohammed, and A. Busalim, Eds., ed: Springer, Cham, 2019, pp. 1090-1099.

[15] A. L. Ramos, J. V. Ferreira, and J. Barceló, "Model-based systems engineering: An emerging approach for modern systems," Systems, Man, and Cybernetics, Part C: Applications and Reviews, IEEE Transactions on, vol. 42, pp. 101-111, 2012.

[16] H. Alaidaros, M. Omar, and R. Romli, “Improving the progress monitoring task of agile Kanban Method: An enhanced theoretical framework and its implication," International Journal of Scientific and Technology Research (IJSTR), vol. 9, pp. 611-615, 2020.

[17] H. AlDarmaki, A. Bhaumik, and I. AlRajawy, "Effect of Total Quality Management Practices in Private Organization in the UAE," International Journal on Emerging Technologies, vol. 10, pp. 115-123, 2019 .

[18] H. Alaidaros, M. Omar, and R. Romli, "Identification of criteria affecting soffware project monitoring task of Agile Kanban method," presented at the AIP Conference Proceedings, 2018.
[19] L. A. Machi and B. T. McEvoy, The literature review: Six steps to success. United States: Corwin Press, 2016.

[20] C. Auerbach and L. B. Silverstein, Qualitative data: An introduction to coding and analysis. USA: New York University press, 2003.

[21] K. Krippendorff, Content analysis: An introduction to its methodology. United States: SAGE Publications, Inc, 2018.

[22] J. W. Creswell, Research design: Qualitative, quantitative, and mixed methods approaches, 4th ed. Thousand Oaks, California: SAGE Publications, Inc., 2016.

[23] S. Easterbrook, J. Singer, M.-A. Storey, and D. Damian, "Selecting empirical methods for soffware engineering research," in Guide to advanced empirical software engineering, ed: Springer, 2008, pp. 285 311.

[24] R. K. Yin, Case study research and applications: Design and methods, 6th ed. Thousand Oaks, United States: SAGE Publications, Inc, 2018.

[25] R. Malhotra, Empirical research in software engineering: concepts, analysis, and applications. United States: CRC Press, 2016.

[26] M. H. A. Altarawneh, "Monitoring oriented Agile based web applications development methodology for small software firms in Jordan," PhD Thesis, UUM, 2016.

[27] R. Hannemann, "Modifying senior design: A design review," in American Society for Engineering Education Annual Conference and Exposition 2009, Austin, Texas, USA, 2009, pp. 10560-10568.

[28] F. Malik, "Syntegrating city management," in Institutional and Social Innovation for Sustainable Urban Development. vol. 258, ed: ROUTLEDGE in association with GSE Research, 2013, pp. 258-274.

[29] U. Sekaran and R. J. Bougie, Research methods for business: A skil building approach, 7th ed. United States: Wiley, 2016.

[30] R. Lovreglio, E. Ronchi, and M. J. Kinsey, "An Online Survey of Pedestrian Evacuation Model Usage and Users," Fire Technology, vol. 56, pp. 1133-1153, 2019.

[31] R. N. Pahurkar, B. V. Sangvikar, K. Khadke, and A. Kolte, “An Exploratory Study of Important Dimensions in Strengthening BuyerSupplier Relationship. ," International Journal on Emerging Technologies, vol. 11, pp. 803-810, 2020.

[32] H. Alaidaros, Omar, M., Romli, R., Hussein, A., "The Development and Evaluation of A Progress Monitoring Prototype Tool for Software Project Management," presented at the 2019 First International Conference of Intelligent Computing and Engineering (ICOICE), Hadhramout, Yemen, 2019.

[33] P. Eriksson and A Kovalainen, Qualitative methods in business research. United States: SAGE Publications, Inc, 2008.

[34] H. Alaidaros, M. Omar, and H. H. Abdullah, "Requirements Modeling for University e-Ranking Dashboard System (e-RDS)," Journal of Engineering and Applied Sciences, vol. 12, pp. 6362-6370, 2017.

[35] M. C. Harrell and M. A. Bradley, "Data collection methods. Semistructured interviews and focus groups," DT IC Document2009.

[36] J. Bräuer, R. Plösch, M. Saff, and C. Körner, "Measuring object-oriented design principles: The results of focus group-based research," Journ al of Systems and Software, vol. 140, pp. 74-90, 2018.

[37] S. F. P. Mohamed, F. Baharom, A. Deraman, and Y. Yusof, "The validation of extended software process assessment and certification model using focus group," in Proceeding of the First International Conference on ICT for Transformation (IC-ICT4T 2016), Kota Kinabalu, Sabah, Malaysia, 2016, pp. 192-197.

[38] A. Bhat. (2018, 16 Sept 2019). Qualitative research: Definition, types, methods and examples. Available: https://www.questionpro.com/blog/qualitative-research-methods/

[39] J. Kontio, J. Bragge, and L. Lehtola, "The focus group method as an empirical tool in soffware engineering," in Guide to advanced empirical software engineering, ed: Springer, 2008, pp. 93-116.

[40] J. Singer, S. E. Sim, and T. C. Lethbridge, "Soffware engineering data collection for field studies," in Guide to Advanced Empirical Software Engineering, ed: Springer, 2008, pp. 9-34.

[41] S. F. P. Mohamed, "A process based approach software certification model for Agile and secure environment," PhD Thesis, UUM, 2015. 
[42] R. A. Krueger and M. A. Casey, Focus groups: A practical guide for applied research. United States: SAGE Publications, Inc, 2014.

[43] V. Wibeck, Focus groups: Focused group interviews as a research method. Lund, Sweden: Studentlitteratur AB, 2010.

[44] J. K. Hummelvoll, "The multistage focus group interview: A relevant and fruit ful method in action research based on a co-operative inquiry perspective," Norsk Tidsskrift for Sykepl eieforskning, vol. 10, pp. 3-14, 2008 .

[45] T. Nyumba, K. Wilson, C. J. Derrick, and N. Mukherjee, "The use of focus group discussion methodology: Insights from two decades of application in conservation," Methods in Ecology and evolution, vol. 9, pp. 20-32, 2018.

[46] D. L. Morgan, Focus groups as qualitative research, 2nd ed. Thousand Oaks, California, USA: SAGE Publications, Inc, 1996.

[47] H. F. Atlam, A. Alenezi, R. K. Hussein, and G. B. Wills, "Validation of an adaptive risk-based access control model for the Internet of Things," International Journal of Computer Network and Information Security, vol. 10, pp. 26-35, 2018.

[48] S. M. Sarif, N. Ibrahim, and N. Shiratuddin, "Design model of computerized personal decision aid for youth: An expert review," in AIP Conference Proceedings, Kedah, Malaysia, 2016.
[49] S. A. Aziz, S. N. A. Salam, A. A. Mutalin, and S. Ismail, "Validating an integrated multimedia presentation conceptual model through expert reviews," Journal of Telecommunication, Electronic and Computer Engineering (JTEC), vol. 8, pp. 161-163, 2016.

[50] E. DeKock, J. Van Biljon, and A. Botha, "User experience of academic staff in the use of a learning management system tool," in the Annual Conference of the South African Institute of Computer Scientists and Information Technologists (SAICSIT 2016), Johannesburg, South Africa, 2016, pp. 15-25

[51] M. Omar, H. Alaidaros, and R. Romli, "An Improved Soffware Project Monitoring Task Model of Agile Kanban Method: A Practitioners' Perspective," International Journal on Advanced Science, Engineering and Information Technology, vol. 10, pp. 120-127, 2020.

[52] B. Shneiderman, C. Plaisant, M. Cohen, S. Jacobs, N. Elmqvist, and N. Diakopoulos, Designing the user interface: Strategies for effective human-computer interaction, 6th ed. Hoboken, United States: Pearson Education Inc., 2016.

[53] R. Molich, \& Jeffries, R., "Comparative expert reviews," presented at the CHI'03 Extended Abstracts on Human Factors in Computing Systems, Lauderdale, USA, 2003. 